\title{
Using of Photoluminescent Tile for Evacuation of the Buildings During Electrical Failure
}

\author{
Neslihan Tamsü Selli and Ayse Tunali \\ Eczacibasi Building Products Co. VitrA Innovation Center Bozuyuk/Bilecik-Turkey
}

Received: March 07, 2014 / Accepted: April 10, 2014 / Published: April 25, 2014.

\begin{abstract}
Photoluminescent pigments could be successfully applied on the wall tiles, floor tiles and porcelain tiles as well as glass substrates (glass mosaics, borders, and cutted glass with various designs). For this applications, these products can be used for different purposes. In this study, these pigments are applied on the ceramic tiles and glass mosaics/tiles with traditional ceramic production line. These products are intentended to provide guidance in the event of a power failure. With this study also aimed to prevent potential accidents and injury during evacuation of building.
\end{abstract}

Key words: Photoluminescent pigments, tiles, evacuation.

\section{Introduction}

The term "luminescence" originates from the Latin word "lumen", which means light and the literal translation from Latin is "weak glow". It was introduced into the scientific literature by Eilhardt Wiedemann, a German physicist, in 1888 [1]. Luminescence, which includes both fluorescence and phosphorescence in which the electronic state of a solid is excited by an external energy and the absorbed energy is given off as visible light. Light is comprised of photons, which are quantized waves exhibiting some of the properties of particles, i.e., wave-particle duality [2]. Photoluminescence (PL) is excited by electromagnetic radiation with short-wavelengths such as ultraviolet light [3]. Inorganic luminescent materials can be divided in two classes [4]: (1) those that absorb light (pigmented) and (2) those that absorb the energy and emit light (phosphors and solid state lasers). In both cases, certain amounts of transition and/or lanthanide ion(s) are incorporated to control the

Corresponding Author: Neslihan Tamsü Selli, Ph.D., research field: traditional ceramics. E-mail: neslihan.tamsu@eczacibasi.com.tr; neslihan.tamsu@gmail.com absorption and emission characteristics of that solid. Phosphors in the strontium aluminates system activated with europium (Eu) and dysprosium (Dy) has a wide range of industrial applications such as phosphor host compounds [5, 6], glazes, pigments [7], electrical insulators [8], and it is an important component in glass ceramics [9]. When these structure compared to the classical sulphur phosphors, they are superior because of their high radiation intensity, color purity, long emission duration, chemical stability and because they are reliable and have no radiation [3]. In this present study, these pigments are applied on the ceramic tiles with traditional ceramic production line. These products are intented to provide guidance in the event of a power failure. With this study also aimed to prevent potential accidents and injury during evacuation of building.

\section{Experiments}

In this study, $\mathrm{SrAl}_{2} \mathrm{O}_{4}$ phosphorescent pigments with long-term phosphorescence which bluish-green denoted as (S) and yellowish-green denoted as (Y), were used in wall tile vetrosa applications. The chemical analysis of the pigments was shown in Table 1. 
Table 1 Chemical compositions of the phosphorescent pigments.

\begin{tabular}{|c|c|c|}
\hline Compositions & (S) & $(\mathrm{Y})$ \\
\hline $\mathrm{SiO}_{2}$ & 32.55 & 0.11 \\
\hline $\mathrm{SrO}$ & 53.29 & 46.29 \\
\hline $\mathrm{Eu}_{2} \mathrm{O}_{3}$ & 0.38 & 0.49 \\
\hline $\mathrm{Fe}_{2} \mathrm{O}_{3}$ & 0.20 & 0.20 \\
\hline $\mathrm{MgO}$ & 11.70 & - \\
\hline $\mathrm{Dy}_{2} \mathrm{O}_{3}$ & 0.64 & 0.84 \\
\hline $\mathrm{CaO}$ & - & 0.08 \\
\hline
\end{tabular}

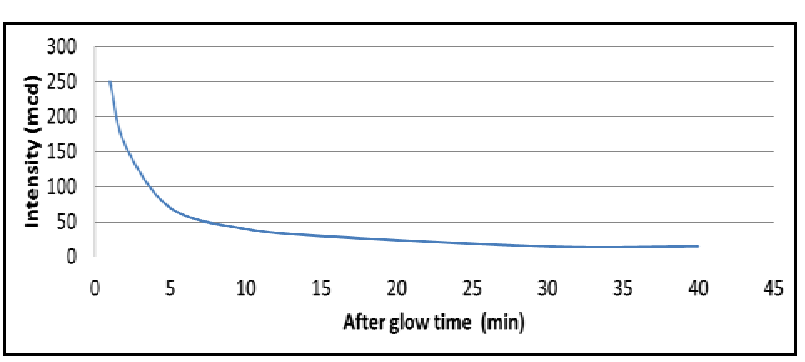

Fig. 1 After glow property of the tiles versus time in the darkness.

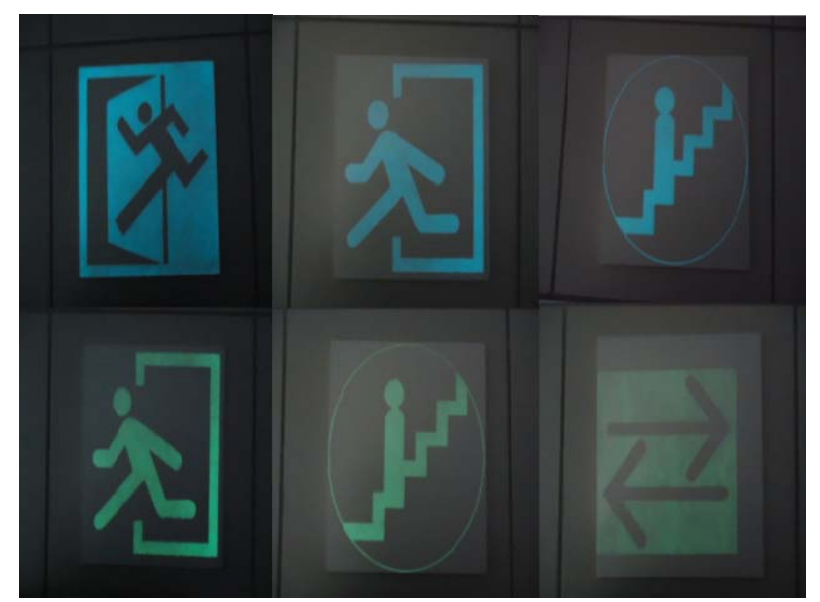

Fig. 2 Images of produced photoluminescent tiles in dark.

After firing, obtained fritted surfaces' after glow property was measured by using Photometer (LS-100, Konica, Minolta). After glow property was determined considering the glowness of the sample in darkness versus time.

\section{Experimental Results}

Tests on wall tile vetrosa applications were carried out for pigments derived in the last stage of the study. Phosphorescent pigment added vetrosa frit with same proportions was applied on glazed tile bodies and third firing was carried out. In the case of emergency situation, first half hour is quite critical in the event of a power failure, for this reason photoluminescent tiles must show glow in the dark in this period. Therefore, pigmented surfaces glowness in order to understand whether it is suitable of use in an emergency exit measured in the dark. Fig. 1 shows the after glow property of the photoluminescent tile, which were excited under light for $5 \mathrm{~min}$, versus time in the darkness. Based on this graph (Fig. 1), the tiles, for first 5 min shows 250 mcd intensity, after 40 min this value decreases to $30 \mathrm{mcd}$. The minimum light detection intensity value in the darkness for human eyes is $0.32 \mathrm{mcd}$. Therefore, developed tiles can be used for emergency exits readily.

The photographs of tiles produced using the optimum parameters derived as a result of the studies are given in Fig. 2.

\section{Conclusions}

Phosphorescent pigment added vetrosa frit with same proportions was applied on glazed tile bodies and third firing was carried out. According to the analyses, it has been found that newly developed photoluminecent tiles can be successfully applied to emergency exits and signs.

\section{References}

[1] E. Wiedemann, Florescence and phosporesence, Annual Physical Chemistry 34 (1888) 446-463.

[2] A. Zukauskas, M.S. Shur, R. Gaska, Introduction to solid-state lighting, John Wiley \& Sons, New York, (2002).

[3] S.K. Yesilay, B. Karasu, Glass and ceramics with phosphorescent ability, Ceramics Technical 34 (2012) 94-99.

[4] V.P. Gribkoskii, Theory of Luminescence, Luminescence of Solids, Plenum Press, New York, 1998, pp. 1-43.

[5] T.H. Cho, H.J. Chang, Preparation and characterizations of $\mathrm{Zn}_{2} \mathrm{SiO}_{4}$ : Mn green phosphors, Ceramics International 29 (2003) 611-613.

[6] Y.C. Kang, H.D. Park, Brightness and decay time of $\mathrm{Zn}_{2} \mathrm{SiO}_{4}$ : Mn phosphor particles with spherical shape and fine size, Applied Physics A 77 (2003) 529.

[7] J. Alarcon, P. Escribano, R.M. Martin, British Ceramics Transactions J. 84 (1985) 170. 
[8] D. Lepkova, A. Nenov, L. Pavlova, I. Ivalnov, Stroit. Materi. Silik. Promst. 21 (1980) 18.
[9] Z. Strands, Glass science and technology, Elsevier, Amsterdam 8 (1986) 101. 